\title{
Copper complexes of phosphorus dendrimers and their properties
}

Omar Alami, ${ }^{a, b, c}$ Régis Laurent, ${ }^{a, b}$ Jean-Pierre Majoral, ${ }^{a, b}$ Nabil El Brahmi, ${ }^{c}$ Said El Kazzouli, ${ }^{c}$ AnneMarie Caminade*a,b

a Laboratoire de Chimie de Coordination, CNRS, 205, route de Narbonne, Toulouse 31077, Cedex 04, France. E-mail addresses: omar.alami@lcc-toulouse.fr; regis.laurent@Icc-toulouse.fr; jean-pierremajoral@Icc-toulouse.fr; anne-marie.caminade@Icc-toulouse.fr

${ }^{\mathrm{b}}$ LCC-CNRS, Université de Toulouse, CNRS, Toulouse, France

' Euromed Research Center, Engineering School of Biomedical \& Biotechnology, Euromed. University of Fes (UEMF), Route de Meknes, 30000 Fes, Morocco. E-mail addresses: n.elbrahmi@ueuromed.org; s.elkazzouli@ueuromed.org

\section{Dedicated to our friend Maurizio Peruzzini on the occasion of his retirement.}

\section{Highlights}

- Phosphorus dendrimers have been functionalized by a large variety of ligands suitable for the complexation of copper

- Copper complexes of phosphorus dendrimers are efficient catalysts in a range of reactions

- Copper complexes of phosphorus dendrimers can be efficiently recovered and reused

\section{Abstract}

Phosphorus dendrimers are highly branched macromolecules, built with one phosphorus atom at each branching point. These dendrimers can be functionalized at will on the terminal functions. Grafting as terminal functions ligands suitable for the complexation of copper has been carried out several times, in particular with the aim of using the corresponding complexes as catalysts in a range of reactions, from $\mathrm{O}-$ and $\mathrm{N}$-arylations and -vinylations, to the asymmetric benzoylation of linear or cyclic diols. $\mathrm{A}$ sequel of this work concerns the study of anticancer activity of analogous dendritic copper complexes.

\section{Graphical abstract}

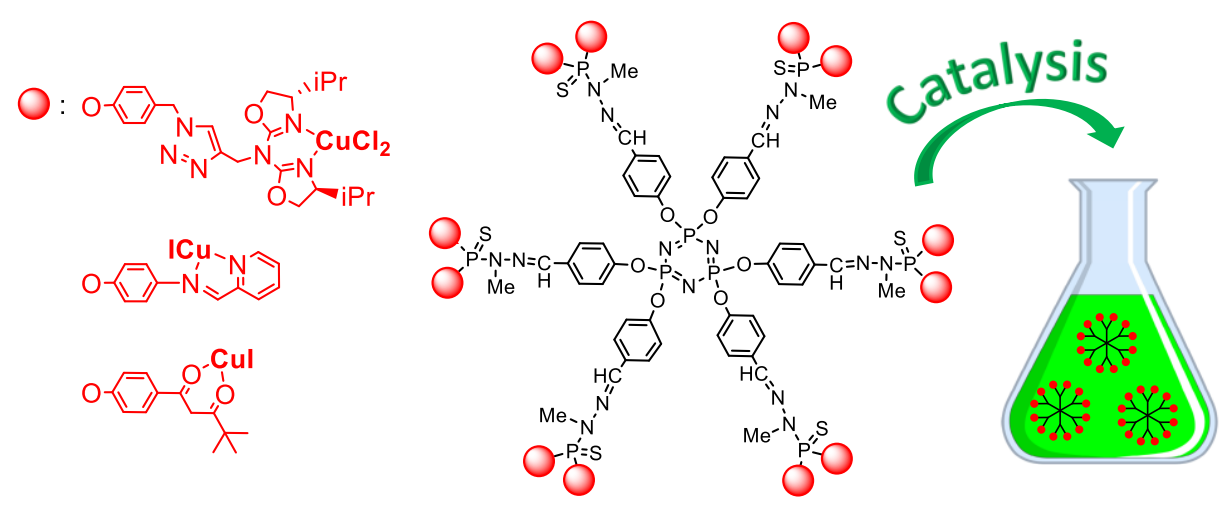

\section{Keywords}

Dendrimers; phosphorus; copper complexes; pyridine imine; diketone; catalysis. 


\section{Introduction}

Dendrimers are highly branched macromolecules, constituted of concentric layers named "generations", which are synthesized step-by-step around a multifunctional central core. The number of terminal functions increases at the end of the synthesis of each generation. The number of terminal functions is most frequently multiplied by 2 at each generation [1], eventually by 3 [2], or even by 5 [3], depending on the number of functions at the branching points. Different types of dendrimers have been synthesized, either purely organic with nitrogen as branching points in most cases [1], or partly inorganic with either phosphorus or silicon as branching points [4]. Drawing dendrimers needs a large space when their size increases, thus they are most generally written in a linear way, with parentheses after each level of branching units. Both types of representations are shown in Figure 1 for a third generation dendrimer.

Most of the properties of dendrimers depend on the type of terminal functions they bear. A number of dendrimers have been functionalized with metal complexes [5], in particular phosphorus-containing dendrimers [6,7]. These dendrimers are essentially of type phosphorhydrazone. Many phosphorhydrazone dendrimers have been functionalized with palladium complexes, and used as catalysts for Suzuki-Miyaura [8-10], Stille $[11,12]$ and Sonogashira $[8,13]$ cross-couplings, for Heck reactions $[8,13,14]$, and for allylic alkylations $[15,16]$. Phosphorhydrazone dendrimers functionalized with ruthenium complexes have been used as catalysts for Knoevenagel condensations and Michael additions [11], hydrogenation reactions [17], hydration of terminal alkynes [18-20] and isomerization of allylic alcohols $[18,21,22]$. Phosphorhydrazone dendrimers functionalized with rhodium complexes were used as catalysts for the isomerization of allylic alcohols [19], and [2+2+2] cycloaddition reactions [23], whereas scandium complexes have been used for catalyzing Friedel-Crafts acylations [24]. In this review, we will focus on another element, copper, complexed on the surface of phosphorhydrazone dendrimers, and on their properties as efficient catalysts.

Different advantages can be expected when using dendrimers as catalysts instead of "classical" monomeric catalysts. Due to their large size, dendrimers are generally slightly less soluble than small catalysts, thus it is generally easy to recover them by precipitation, using a solvent in which the products will be soluble, but not the dendrimers. Another possibility for recovery is ultra-filtration through a membrane, also possible thanks to the large size of dendrimers. Such recovery and reuse are desirable to decrease the cost associated to dendrimers. The presence of a large number of catalytic entities in close proximity on the surface of dendrimers might induce a synergy or a cooperativity, increasing the catalytic efficiency and/or the enantioselectivity. This may permit to decrease the temperature needed to perform the reaction, or to decrease the time needed for the reaction to go to completion. In some cases, a decrease in the metal leaching can be also observed.

All these particular properties of dendrimers are gathered under the concept of "dendrimer (or dendritic) effect" [25]. This effect is observed when a functional group behaves differently when it is alone or linked to a dendrimer, and it is a true non-linear effect, which can induce quite remarkable properties. The origin of such effect is not always fully understood, but has generally to be related to the concept of multivalency, in which stronger effects are observed when several functions are gathered in a single entity. A high local concentration of functions within well-defined nanoscopic reaction volumes can be attained with dendrimers, modifying the molecular interaction with their surrounding at the interface, which in turn affects the activity and selectivity. Such behavior cannot be replicated in randomly dispersed polymeric system. Of course, the efficiency between a monomer and diverse generations of dendrimers has to be compared for the same number of active sites. It must be emphasized that this dendrimer effect is not always positive, but there is a bias in the literature, as positive effects are more easily published than negative effects, especially concerning catalysis. 


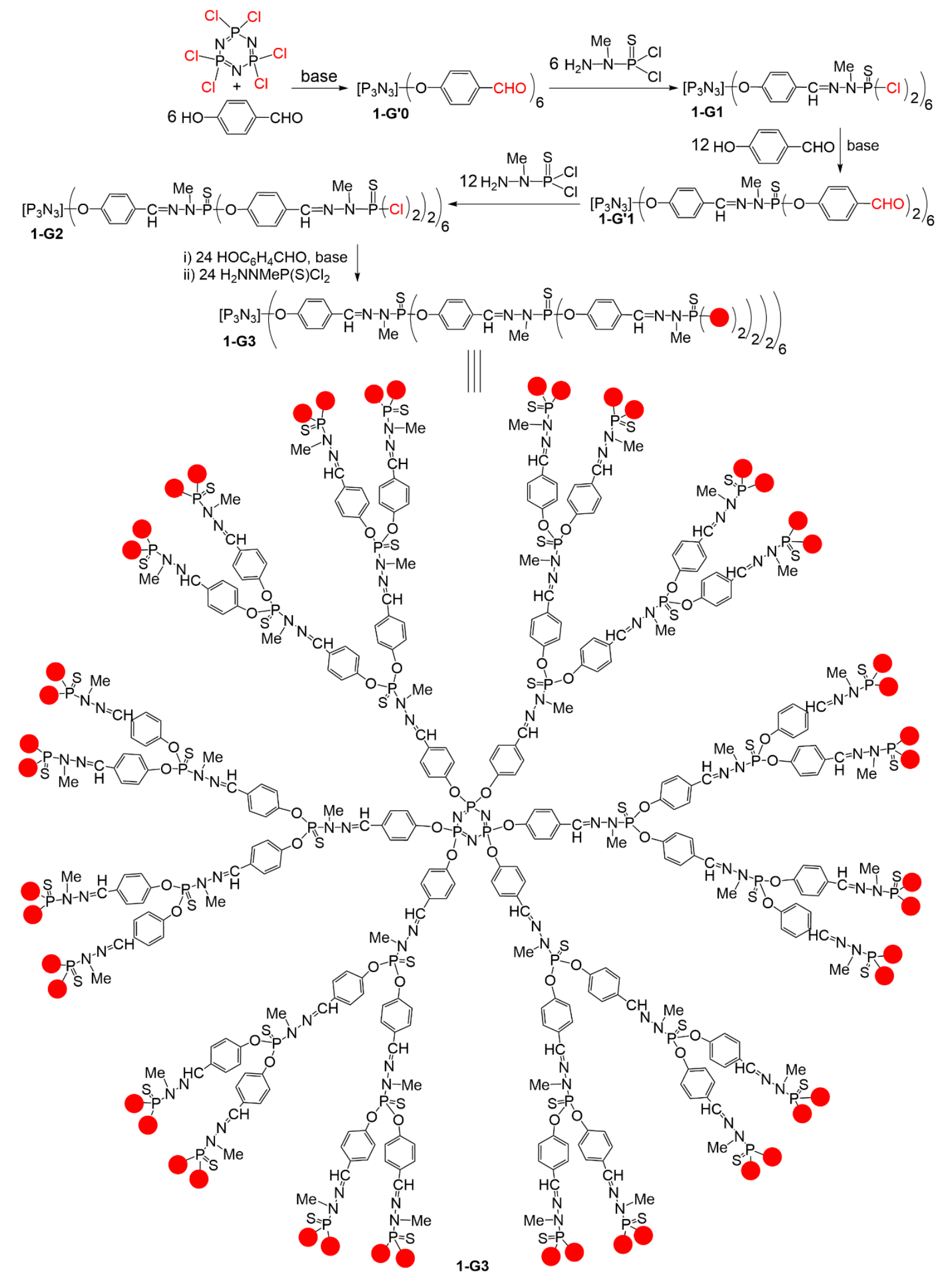

Figure 1. Step-by-step synthesis of phosphorhydrazone dendrimers and structure of a $3^{\text {rd }}$ generation phosphorus dendrimer, drawn in two ways, either the full structure, or the linear structure with a parenthesis after each branching point. The red dots indicate the possible modifications of the surface $[26,27]$. 


\section{Dendritic copper complexes for catalysis}

In general, several generations of dendrimers are synthesized, using a two-step process for each generation, as shown in Figure $1[26,27]$. The synthesis starts with the reaction of six equivalents of 4hydroxybenzaldehyde in basic conditions, generally using cesium carbonate, on hexachlorocyclo triphosphazene $\left(\mathrm{N}_{3} \mathrm{P}_{3} \mathrm{Cl}_{6}\right)$ used as core, to generate compound 1-G'0. The second step is the condensation of the phosphorhydrazide $\mathrm{H}_{2} \mathrm{NNMeP}(\mathrm{S}) \mathrm{Cl}_{2}$, obtained by reaction of methyl hydazine on $\mathrm{P}(\mathrm{S}) \mathrm{Cl}_{3}$ at low temperature. Such condensation affords the first-generation dendrimer 1-G1, having 12 $\mathrm{Cl}$ on the surface, to be compared with the core which had $6 \mathrm{Cl}$. Starting from dendrimer 1-G1, both steps are repeated, i.e. the nucleophilic substitution on the $\mathrm{P}-\mathrm{Cl}$ functions with $12 \mathrm{HOC}_{6} \mathrm{H}_{4} \mathrm{CHO}$ in basic conditions to afford compound 1-G'1, followed by the condensation with 12 equivalents of $\mathrm{H}_{2} \mathrm{NNMeP}(\mathrm{S}) \mathrm{Cl}_{2}$, to afford the second generation 1-G2. This two-step synthesis can be repeated many times, and was carried out up to the twelfth generation 1-G12, which is one of the largest dendrimers ever synthesized [28]. The presence of either $\mathrm{P}(\mathrm{S}) \mathrm{Cl}_{2}$ or aldehyde terminal functions offers a large palette of reactions on the surface of this family of dendrimers, to fulfil the desired properties [29].

Many reactions on the surface of these phosphorhydrazone dendrimers were carried out to graft ligands, to complex different metals, to study their catalytic properties and to compared their efficiency with that of the corresponding monomer. The experiments are generally carried out up to the third or fourth generation of the dendrimers. It must be emphasized that the quantity of metal is identical for experiments which are compared. This means that for the comparison between a monomer and a $3^{\text {rd }}$ generation dendrimer, if 1 equivalent of the third generation is used, its efficiency will be compared with that of 48 equivalents of the monomer, as the $3^{\text {rd }}$ generation dendrimer is functionalized with 48 terminal functions (Figure 1).

Copper is cheaper than "classical" transition metals used in catalysis and is generally believed to be less toxic, thus copper complexes are attractive for catalysis and their use has been previously reviewed [30]. The grafting of copper complexes onto the surface of phosphorhydrazone dendrimers had been successfully carried out a long time ago. Generations 1 to 3 dendrimers have been decorated with pyridine imine ligands, obtained by condensation of 4-aminophenol with 2pyridinecarboxaldehyde, then grafted to the dendrimers bearing $\mathrm{P}(\mathrm{S}) \mathrm{Cl}_{2}$ terminal functions. These pyridine-imine dendrimers were then used for the complexation of $\mathrm{Cul}$, as shown in Figure 2 . The three generations $\mathbf{2 - G 1}$ to $\mathbf{2 - G 3}$, as well as the corresponding monomer $\mathbf{2 - M}$, have been used as catalysts in several coupling reactions [31]. A first example concerns the coupling of 3,5-dimethylphenol with phenyl iodide at $80^{\circ} \mathrm{C}$ in acetonitrile with $\mathrm{K}_{3} \mathrm{PO}_{4}$ as a base, using $10 \mathrm{~mol} \%$ of $\mathrm{Cu}$ (Figure $2 \mathrm{~A}$ ). This loading was chosen so that the ratio $\mathrm{N}, \mathrm{N}$-chelate-to-copper is equal to 1 in all cases. In these conditions, the third generation 2-G3 was the most efficient catalyst, as it improved the catalytic efficiency, compared to the other generations and to the monomer 2-M (graph in Figure 2A). The third generation 2-G3 was still very active when lowering the temperature to $55^{\circ} \mathrm{C}$, whereas the coupling with the monomeric catalyst 2-M was by far less efficient in these conditions. The same family of copper complexes has been used as catalysts in the arylation of pyrazole with aryl halides (phenyl iodide or bromide) at $80^{\circ} \mathrm{C}$ in acetonitrile with $\mathrm{Cs}_{2} \mathrm{CO}_{3}$ as a base in the presence of $10 \mathrm{~mol} \%$ of catalyst (Figure 2B). Under these conditions, the monomer $\mathbf{2 - M}$ has no activity, but a quantitative conversion was observed with all dendrimers for the coupling of phenyl iodide with pyrazole. The less expensive and less reactive bromobenzene induced a strongly positive "dendritic effect" [25], the monomer being non-active, while the catalytic efficiency of the dendrimers increased when the generation increased (graph in Figure 2B). The next step with these catalytic copper complexes consisted in the vinylation of 3,5dimethylphenol and of pyrazole with $E$ - $\alpha$-bromostyrene, at very mild temperature $\left(25^{\circ} \mathrm{C}\right)$. The vinylation of 3,5-dimethylphenol (Figure $2 \mathrm{C}$ ) afforded the corresponding $E$-styrylarylether in $91 \%$ yield 
using the $3^{\text {rd }}$ generation dendrimer 2-G3 as catalyst, whereas a poor conversion of only $35 \%$ was obtained with the monomeric catalyst 2-M. The vinylation of pyrazole (Figure 2D) quantitatively occurred at $25{ }^{\circ} \mathrm{C}$ within 4 days when using the $3^{\text {rd }}$ generation dendrimer 2-G3, whereas the Estyrylpyrazole was obtained in only $70 \%$ yield when using the monomer $\mathbf{2}-\mathbf{M}$ in the same conditions. All these catalytic reactions were carried out in the mildest conditions ever reported at that time using copper complexes as catalysts [31].

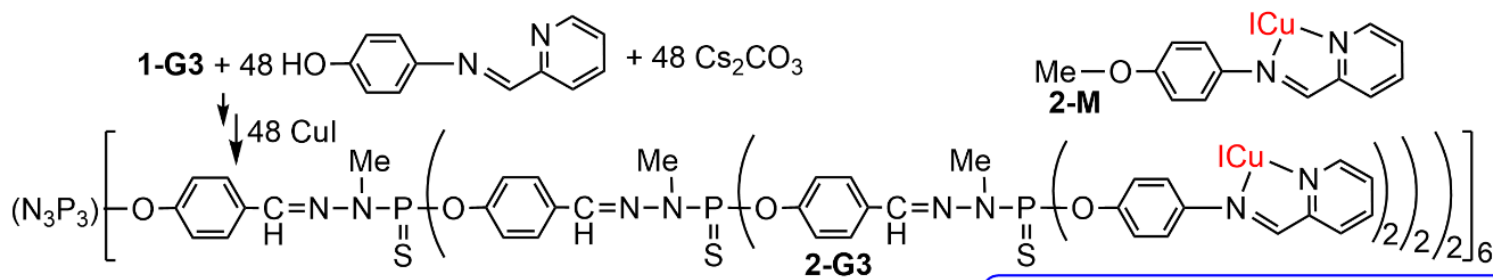

A

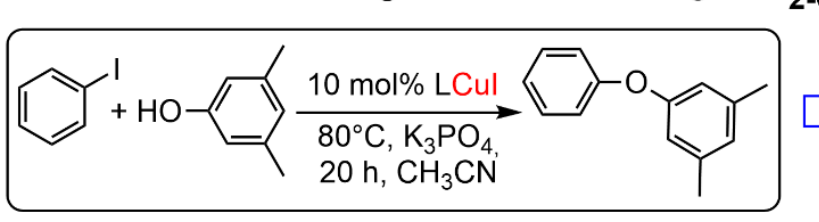

B

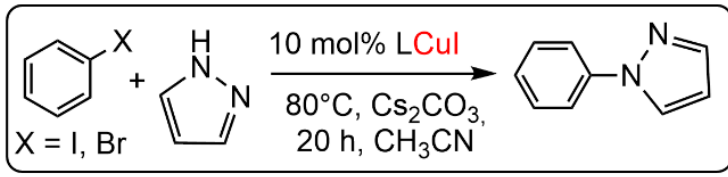

C
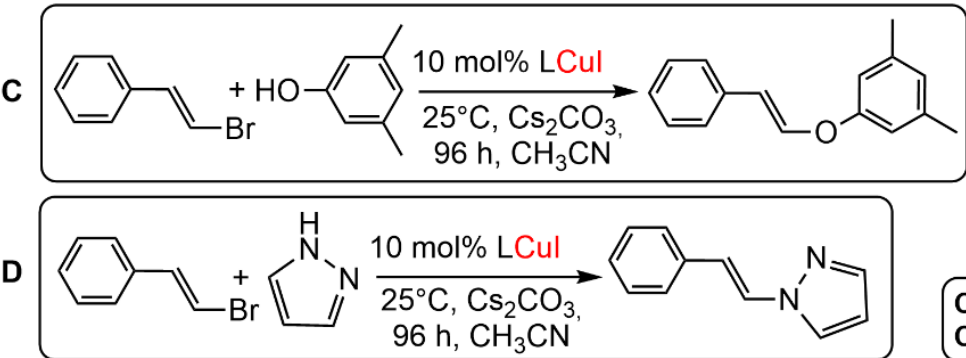

Coupling of dimethyl phenol with $\mathrm{Phl}$
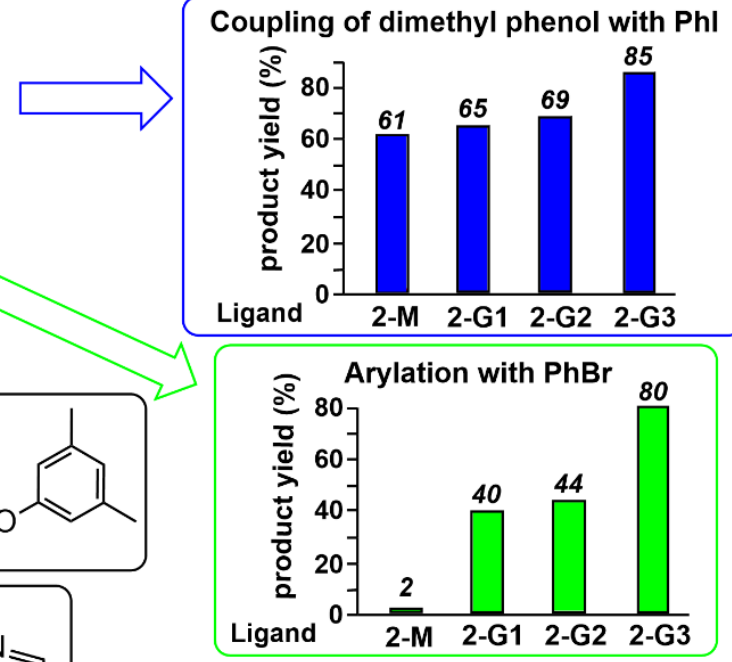

Case C, product yield: 2-M 70\%; 2-G3 100\% Case D, product yield: 2-M 35\%; 2-G3: $91 \%$

Figure 2. Synthesis of the $3^{\text {rd }}$ generation dendrimer 2-G3 functionalized with pyridine imine complexes of Cul. This dendrimer, as well as generations 1 and 2, and the corresponding monomer 2-M were used as catalysts in the coupling reactions shown in cases $\mathbf{A}$ and $\mathbf{B}$. Only the monomer $\mathbf{2}-\mathbf{M}$ and dendrimer 2-G3 were used in cases $\mathbf{C}$ and $\mathbf{D}$ [31].

The second example of copper complexes as terminal functions of phosphorus dendrimers from generation 1 to 3 concerned azabis(oxazoline) ligands. Two families were synthesized. In the first case, the bisoxazoline ligand was functionalized with a phenol, suitable for the reaction with dendrimers ended by $\mathrm{P}(\mathrm{S}) \mathrm{Cl}_{2}$ functions (1-Gn, $\mathrm{n}=1-3$ ) as shown for the synthesis of 3-G3A (Figure $3 \mathrm{~A}$ ). In the second case, the dendrimers with aldehydes terminal functions (1-G'n) were first modified to get azide terminal functions. The next step was a copper-catalyzed azide-alkyne cycloaddition (CuAAC) reaction with a bisoxazoline functionalized by an alkyne, to form a benzyl triazole linker (3-G3B, Figure 3B). These dendrimers were used for the complexation of $\mathrm{CuCl}_{2}$ (one $\mathrm{Cu}$ per bisoxazoline ligand) and evaluated as catalysts in asymmetric benzoylations of diols. The maximum yield obtainable in these reactions starting from a racemic diol is $50 \%$ as only one isomer is expected to react. The first attempts were carried out with both families of dendrimers and the corresponding monomer 3-M using $5 \mathrm{~mol} \%$ of $\mathrm{CuCl}_{2}$ in $\mathrm{CH}_{2} \mathrm{Cl}_{2}$ at $0^{\circ} \mathrm{C}$ for catalyzing the asymmetric benzoylation of racemic hydrobenzoin (Figure 3C). The best catalytic efficiency for the dendrimer of the 3-GnA family was observed with the second generation 3-G2A (41\% yield, $80 \%$ ee), but all generations behaved almost identically. The best catalytic efficiency for the dendrimer having the triazole linker (3-GnB) was also observed with the second generation ( $28 \%$ yield, $86 \%$ ee), but for this family, the third generation has a very poor 
efficiency concerning both the yield and the enantioselectivity (ee), probably due to its lower solubility. One of the interesting properties of catalytic dendrimers is the possibility to recover and to reuse them many times by precipitation, in particular with hexane $[10,24]$. In this perspective, the triazole family was found superior to the tyramine family (see left graph in Figure 3), as yield and ee were almost identical at the first and third use. For this reason, the next experiment concerning the catalyzed benzoylation of trans-cyclohexanediol was only carried out with the triazole family 3-GnB (Figure 3D). The $1^{\text {st }}$ generation dendrimer 3-G1B was very efficient, with $99 \%$ ee even after the third run. The second generation afforded also 99\% ee for the first and second runs, but a slight decrease was observed with the $3^{\text {rd }}$ run (ee $=95 \%$ ). The third generation, here also, was less efficient (see the graph on the right in Figure 3). In a last series of experiments, the triazole-azabisoxazoline ligand was grafted to other supports, "MeO-PEG" and polystyrene, but these compounds were found to be far less efficient than the dendrimers, in particular in terms of ee, which were only 63 and $66 \%$, respectively. This result emphasizes the positive role of dendrimers in catalysis over polymers, presumably due to a better accessibility of the reagents to the catalytic sites on the surface of dendrimers [32].

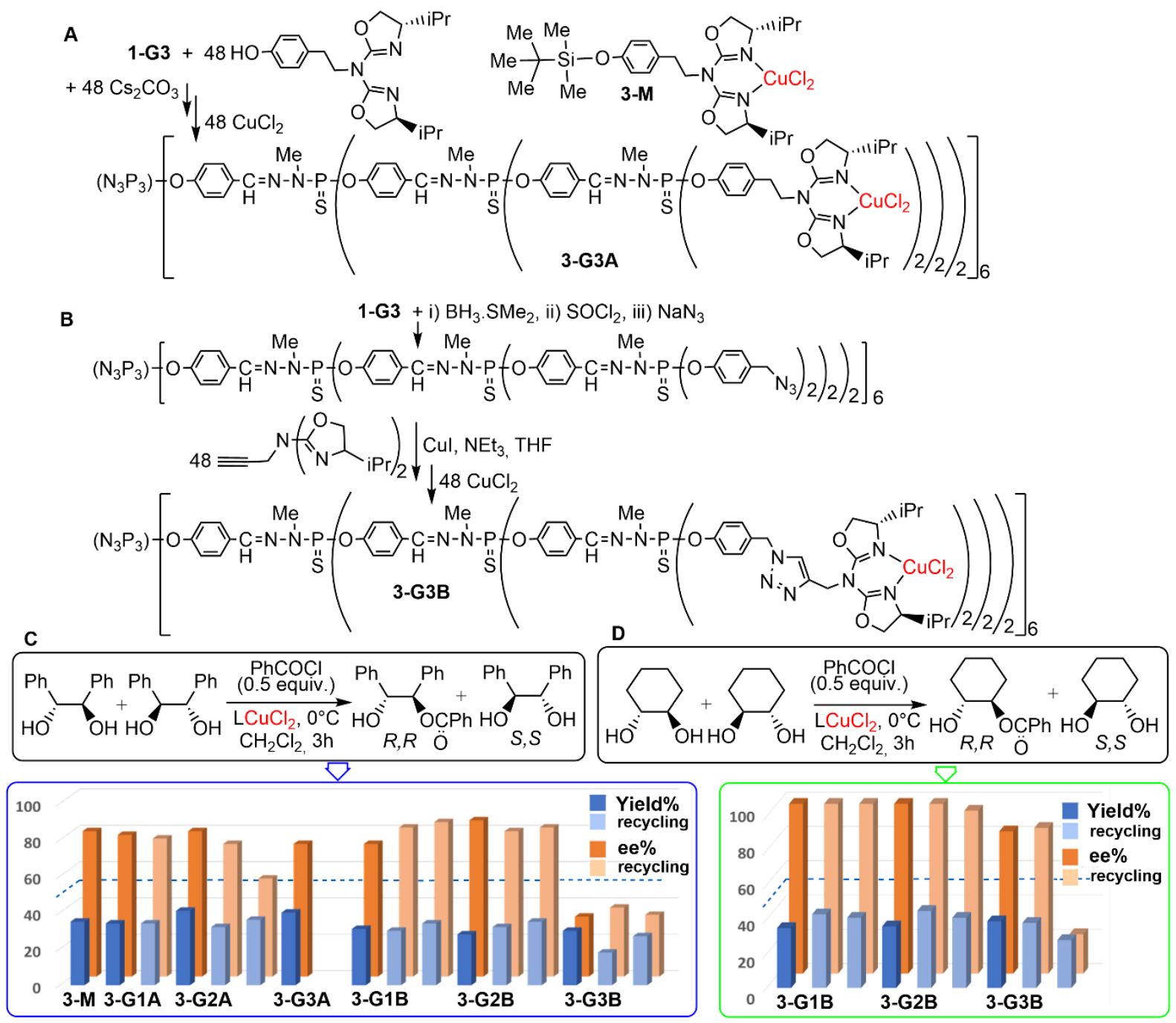

Figure 3. Synthesis of two $3^{\text {rd }}$ generation dendrimers (3-G3A and 3-G3B) and the monomer 3-M functionalized with azabis(oxazoline) complexes of $\mathrm{CuCl}_{2}$, used as catalysts in the asymmetric benzoylation of a linear diol (C) and a cyclic diol (D). Doted lines indicate the maximum theoretical yield (50\%). First experiments are represented in plain colors, whereas recycling experiments are represented in faint colors in graphs $\mathbf{C}$ and $\mathbf{D}$, for both the yield and the enantioselectivity [32]. All the given yields correspond to isolated yields after column chromatography. 
Phosphorhydrazone dendrimers, from generation 0 to generation 4 , functionalized with $\beta$-diketones on their surface, were also able to complex copper, and they were used as catalysts. The first step of the synthesis consisted in the reaction of 4-hydroxyacetophenone with methyl pivalate to get the phenol diketone, which was then grafted to dendrimers with $\mathrm{P}(\mathrm{S}) \mathrm{Cl}_{2}$ terminal functions (Figure 4). The diketone moieties of these dendrimers 4-Gn $(n=0-4)$ were then used for complexing Cul. Either 2 or 4 diketone moieties per Cul were used; the generation 4 (4-G4) with two diketone moieties per $\mathrm{Cu}$ is shown in Figure 4, as well as the monomer 4-M. In a first attempt, the arylation of 3,5-dimethylphenol by bromobenzene was carried out in $\mathrm{DMF}$ at $110^{\circ} \mathrm{C}$ in the presence of $\mathrm{Cs}_{2} \mathrm{CO}_{3}$ as a base, and with 1 mol\% of catalyst. The best results were obtained with 4 diketone moieties per Cul, as shown in the left graph of Figure 4. The reaction yields are almost identical when using the monomer (4-M) or generations 1 to 3 of the dendrimers 4-Gn, but a slightly better efficiency was obtained with the second generation 4-G2. The same reaction was then carried out at $120^{\circ} \mathrm{C}$, using per Cul 4 diketone moieties of the monomer 4-M and all generations of the dendrimers 4-Gn, from 0 to 4 (right graph in Figure 4). The same type of reaction was then carried out with 4-bromoanisole and 4-bromoacetophenone, using the $2^{\text {nd }}$ generation dendrimer $4-\mathbf{G} 2$ at $120^{\circ} \mathrm{C}$ in DMF to afford the corresponding coupled products in 56 and $96 \%$ yield, respectively. Unexpectedly, all attempts carried out to recover and reuse the dendrimers failed. A careful analysis of the outcome of the reaction revealed the presence of unexpected products, which were issued from the nucleophilic substitution of 3,5-dimethylphenoxyde onto the peripheral and internal P-O bonds of the dendrimers. Such substitution onto the P-O bonds was found to be fast, as the dendrimers were quantitatively disintegrated into monomers within 3 hours in the hard conditions of these catalytic reactions [33]. The absence of dendrimer effect and the impossibility to recover and reuse the dendritic catalyst is frequently observed and reported in the literature, but no explanation is generally given. Our work offers an explanation that might be expanded to many other cases in which recovery and reuse of the dendrimer was not possible.

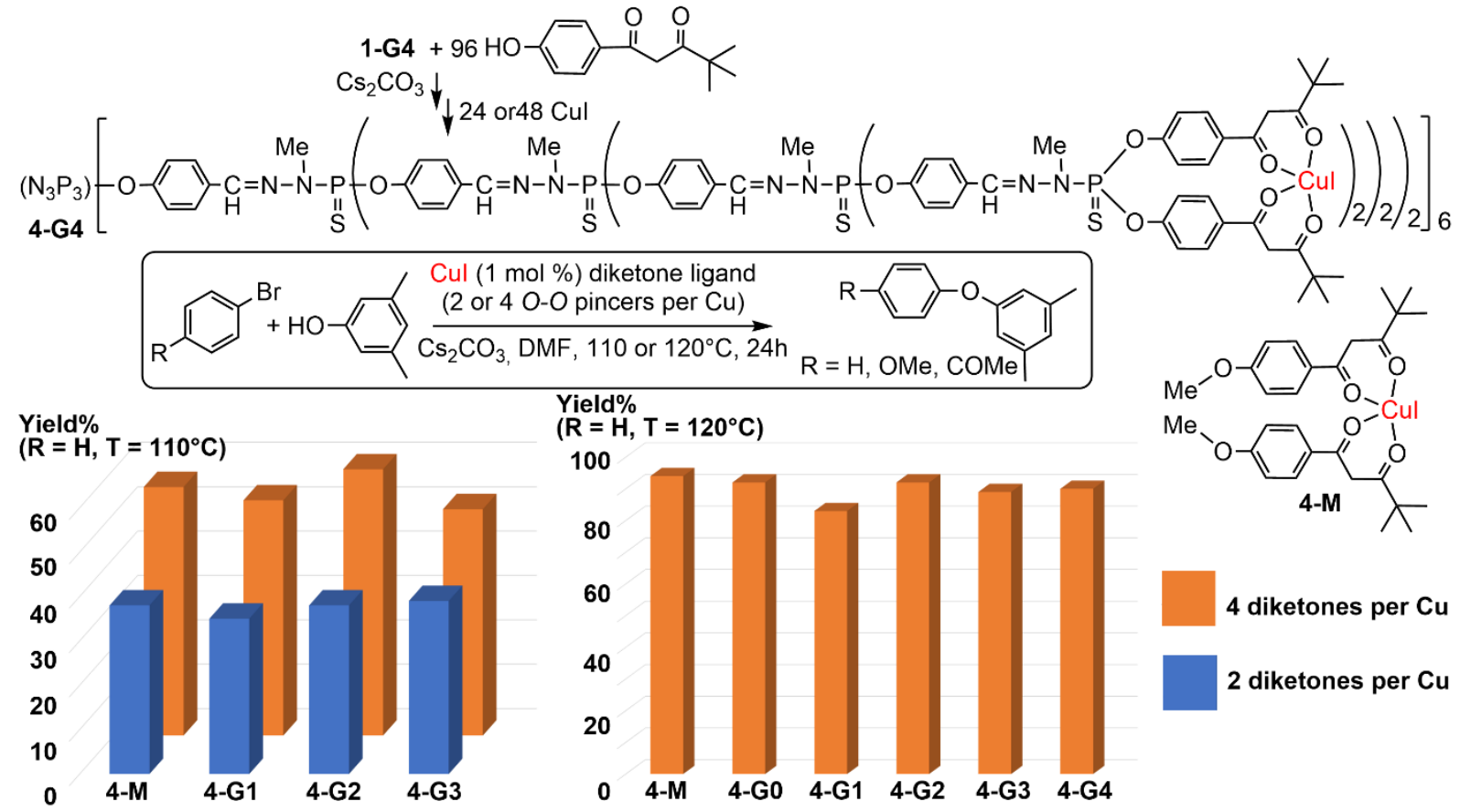

Figure 4. Synthesis of dendrimer 4-G4 functionalized with diketone moieties for the complexation of $\mathrm{Cu}(\mathrm{I})$, and the corresponding monomer 4-M. Generations 0 to 4 were used as catalysts in the arylation of 3,5-dimethylphenol by bromobenzene $(\mathrm{R}=\mathrm{H})$ using either 2 or 4 diketone moieties per $\mathrm{Cu}$ at $110^{\circ} \mathrm{C}$ (graph on the left) or $120^{\circ} \mathrm{C}$ (graph on the right); only the cases where 2 diketone moieties per Cu were used are shown. Dendrimer 4-G2 was also used in the arylation of 3,5-dimethylphenol by 4bromobenzene, 4-bromoanisole and 4-bromoacetophenone [33]. 


\section{A sequel of the use of dendritic copper complexes}

In view of the ease with which the pyridine imine complexes shown in Figure 2 were obtained, this concept has been expanded for the synthesis of other types of pyridine-imine copper complexes. The first chelator was obtained by the condensation of tyramine with 2-pyridinecarboxaldehyde, affording $\mathrm{N}$-(pyridin-2-ylmethylene) ethanamine functions, which were then grafted to the surface of dendrimers having $\mathrm{P}(\mathrm{S}) \mathrm{Cl}_{2}$ terminal functions 1-Gn, to afford the family of dendrimers 5-GnA (Figure 5A). The same process was applied to other ligands, starting from dendrimers 1-Gn. Tyramine was also used for the condensation with di(2-pyridyl) ketone, affording $\mathrm{N}$-(di(pyridin-2-yl)methylene) ethanamine ligands on dendrimers 5-GnB (Figure 5B). Finally, the condensation reaction of 4hydroxybenzaldehyde with 2-hydrazinopyridine yielded 2-(2-methylenehydrazinyl)-pyridine as terminal functions of dendrimers 5-GnC (Figure 5C). In the three cases, the ligands were grafted to dendrimers of generations 1,2 , and 3 . These dendrimers were then used for the complexation of $\mathrm{CuCl}_{2}$, using $1 \mathrm{Cu}$ per chelator unit, then they were tested against several cancerous cell lines. The $\mathbf{A}$ family (5-GnA) was found the most efficient at $1 \mu \mathrm{M}$ [34]. This family was shown the most stable in solution by comparative electron paramagnetic resonance (EPR) studies [35], and the biological mechanism of action has been elucidated [36].

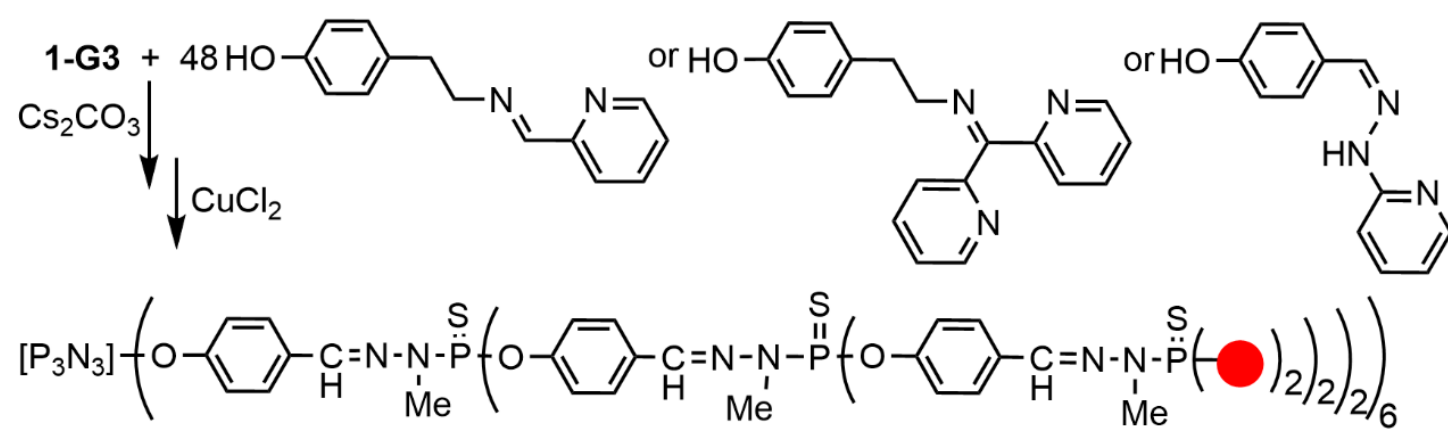

5-G3A, 5-G3B, 5-G3C

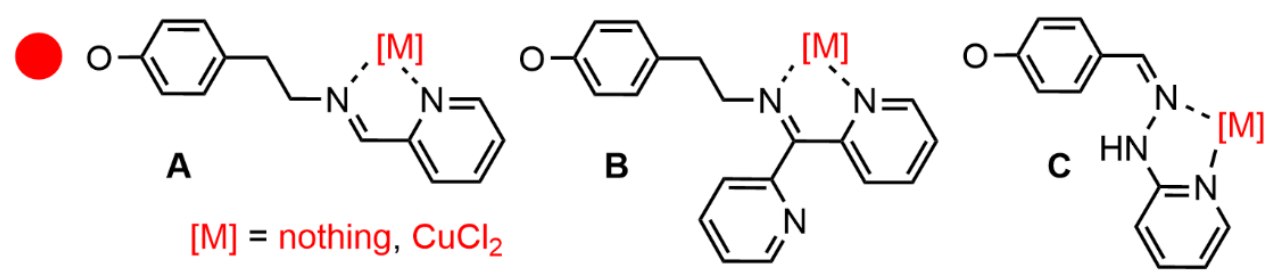

Figure 5. Different types of pyridine-imine functions which have been linked to the surface of dendrimers, from generation 1 to generation 3, and their copper complexes, with one metal per pyridine imine function [34].

The pyridine imine ligands are able to complex different types of metals, and thus an attempt was made to complex $\mathrm{AuCl}_{3}$ instead of $\mathrm{CuCl}_{2}$. Surprisingly, using 1 equivalent of $\mathrm{AuCl}_{3}$ per terminal function resulted in the complexation of only half of these functions. The reason is that $\mathrm{AuCl}_{3}$ is not complexed, but $\mathrm{AuCl}_{2}{ }^{+}$, with $\mathrm{AuCl}_{4}{ }^{-}$as counter-ion, as shown in Figure 6 for dendrimer 6-G3A. A two-order of magnitude increase in the anti-cancer efficiency was observed on going from copper to gold. In view of this striking result, several examples of stochastic functionalization on the surface of the dendrimer have been attempted. An example is shown in Figure 6, in the case 20/10/10/8 (copper/free ligand/gold/PEG), which is one of the most efficient compounds [37]. In addition to the copper and gold complexes, the iron complex $\left(\mathrm{FeCl}_{2}\right)$ of the $\mathbf{A G}_{3}$ dendrimer has been also synthesized and tested, but its antiproliferative activity is by far lower than that of copper [38]. 


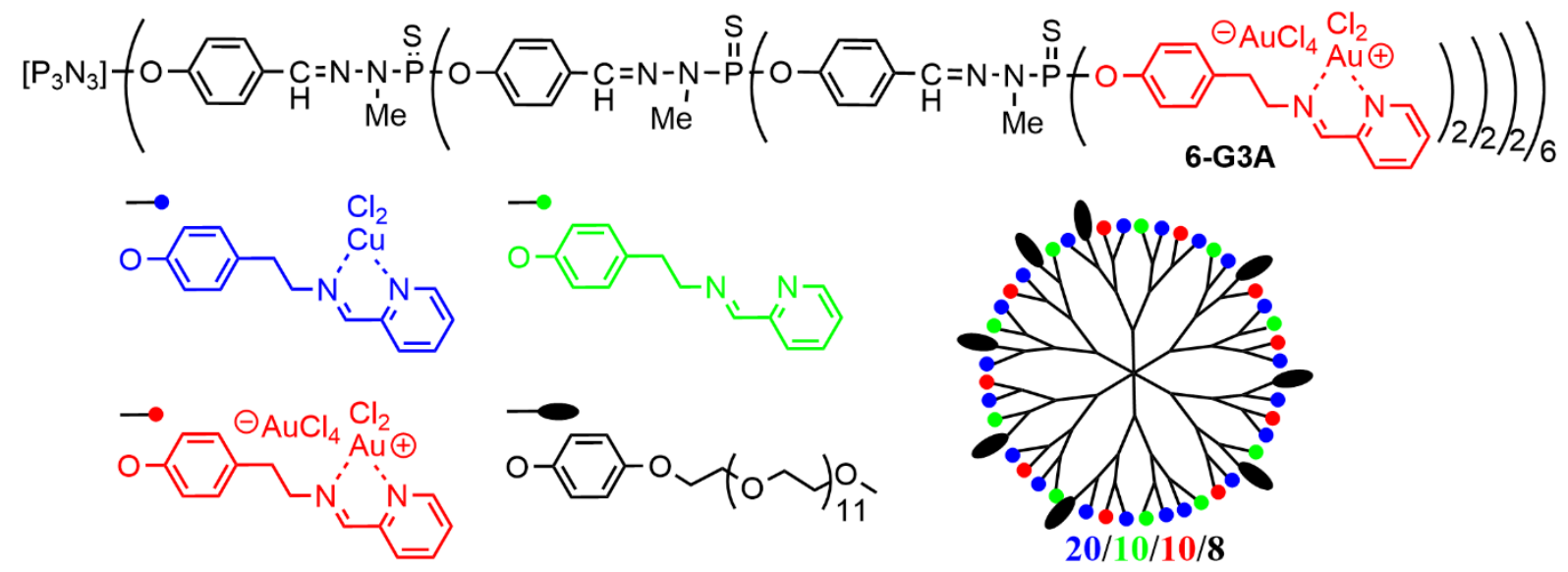

Figure 6. Third generation dendrimer complexing gold on all the terminal functions (6-G3A), and stochastic functionalization on the surface of generation 3 phosphorhydrazone dendrimers. Only one of the numerous possible isomers is shown [37].

Besides dendrimers, dendrons (dendritic wedges) were also functionalized with copper (or gold) complexes on their surface. They were obtained by the specific reactivity of one function of the cyclotriphosphazene core, different from the 5 others [39]. In the first step, five hydroxybenzaldehyde groups were grafted to $\mathrm{N}_{3} \mathrm{P}_{3} \mathrm{Cl}_{6}$, instead of six for the normal synthesis of dendrimers. The remaining $\mathrm{Cl}$ was then replaced by a phenol functionalized with a long alkyl chain. Two different chain lengths for the function at the core were used, $\mathrm{C}_{11} \mathrm{H}_{23}$ and $\mathrm{C}_{17} \mathrm{H}_{35}$. The next step was the classical reaction for the synthesis of dendrimers, i.e. the condensation of the aldehydes with $\mathrm{H}_{2} \mathrm{NNMeP}(\mathrm{S}) \mathrm{Cl}_{2}$. Such reaction was followed by the grafting of $\mathrm{N}$-(pyridin-2-ylmethylene) ethanamine functions to the $\mathrm{P}(\mathrm{S}) \mathrm{Cl}_{2}$ terminal functions, as already shown in Figure 5. In the final step, two metals were complexed on the surface, either copper or gold, affording 4 different first generation dendrons, depending on the length of the chain at the core and the type of metal complexed on the surface 7a-G1Cu, 7b-G1Cu, 7a-G1Au, and 7b-G1Au (Figure 7). These dendrons were found active against several aggressive breast cancer cell lines [40].

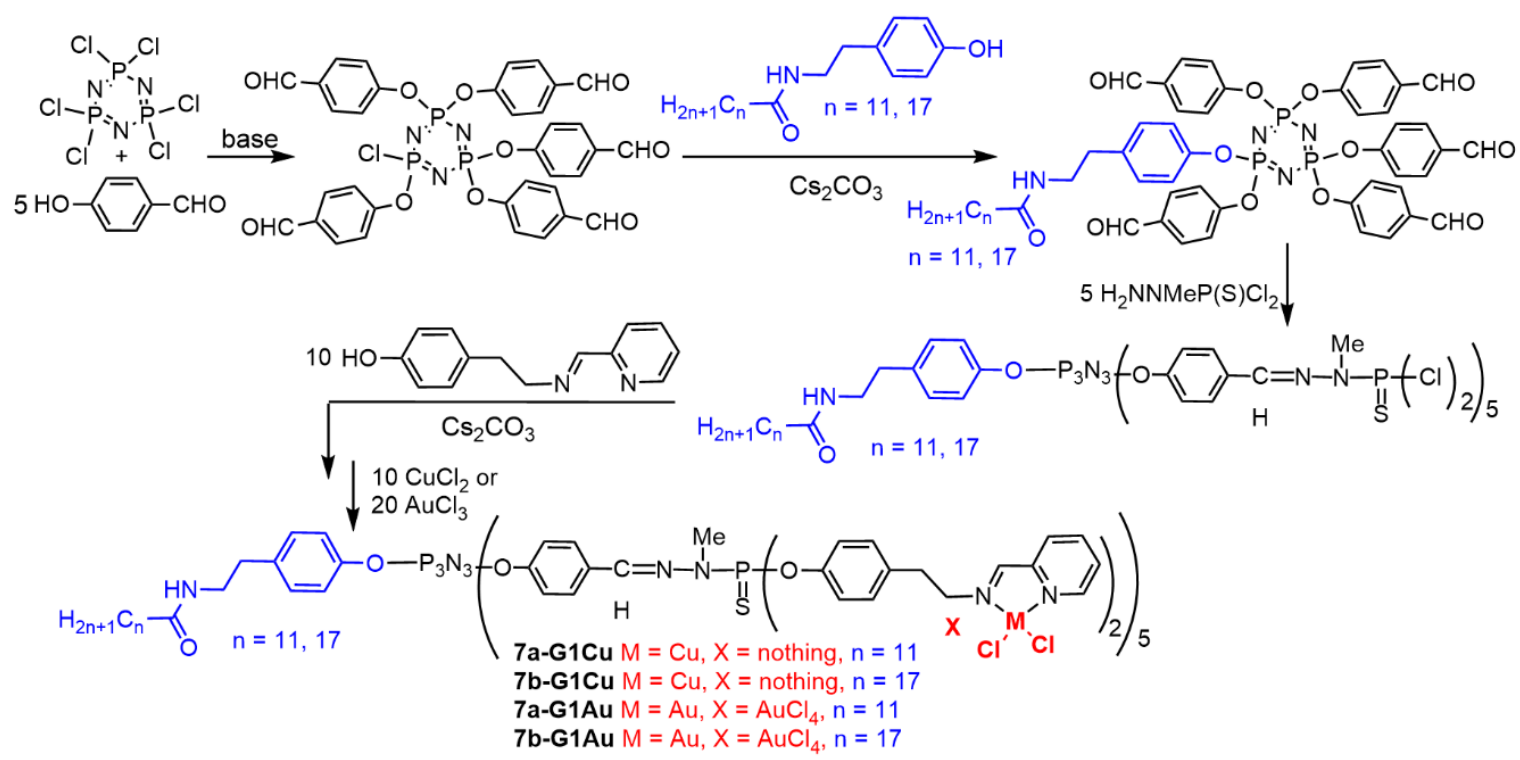

Figure 7. Chemical structure of first generation dendrons having a long alkyl chain $\left(C_{11}\right.$ or $\left.C_{17}\right)$ linked to the core, and either copper (7-G1Cu) or gold (7-G1Au) complexes as terminal functions [40]. 


\section{Conclusion}

We have shown in this review that copper complexes of phosphorhydrazone dendrimers have an interesting potential in catalysis. Different types of ligands were synthesized and grafted to the surface of dendrimers. It should be emphasized that our approach was not to find the best catalysts, but to demonstrate that even very poor monomeric catalysts can become highly efficient when grafted on the surface of dendrimers. Pyridine imine ligands complexing Cul were used as efficient catalysts in Oand $\mathrm{N}$-arylations and -vinylations, and demonstrated a very positive dendritic effect. Azabis(oxazoline) complexes of $\mathrm{CuCl}_{2}$ were used as reusable catalysts in the asymmetric benzoylation of a linear diol or a cyclic diol in mild conditions. Dendrimers functionalized with diketone moieties for the complexation of copper were used as catalysts in the arylation of 3,5-dimethylphenol by diverse derivatives of bromobenzene. As a sequel of this work about catalysis, diverse types of pyridine imines complexing copper have been synthesized and then tested against various types of cancerous cell lines. In view of these results, it appears that dendritic copper complexes have still a large potential in catalysis, and may be also in biology.

\section{Aknowledgements}

The authors, and specially O.A. thank TOUBKAL/19/88: 41405WE for financial support.

\section{References}

[1] G.R. Newkome, C.D. Shreiner, Polymer, 49 (2008) 1-173. https://doi.org/10.1016/j.polymer.2007.10.021

[2] G.R. Newkome, C. Shreiner, Chem. Rev., 110 (2010) 6338-6442. https://doi.org/10.1021/cr900341m

[3] V. Maraval, A.M. Caminade, J.P. Majoral, J.C. Blais, Angew. Chem. Int. Ed., 42 (2003) 1822-1826. https://doi.org/10.1002/anie.200250827

[4] A.M. Caminade, Chem. Soc. Rev., 45 (2016) 5174-5186. https://doi.org/10.1039/c6cs00074f

[5] S.H. Hwang, C.D. Shreiner, C.N. Moorefield, G.R. Newkome, New J. Chem., 31 (2007) 1192-1217. https://doi.org/10.1039/b612656c

[6] M. Slany, M. Bardaji, A.M. Caminade, B. Chaudret, J.P. Majoral, Inorg. Chem., 36 (1997) 1939-1945. https://doi.org/10.1021/ic961258m

[7] A.-M. Caminade, R. Laurent, Coord. Chem. Rev., 389 (2019) 59-72. https://doi.org/10.1016/j.ccr.2019.03.007

[8] P. Servin, R. Laurent, A. Romerosa, M. Peruzzini, J.P. Majoral, A.M. Caminade, Organometallics, 27 (2008) 2066-2073. https://doi.org/10.1021/om800008p

[9] M. Keller, A. Hameau, G. Spataro, S. Ladeira, A.M. Caminade, J.P. Majoral, A. Ouali, Green Chem., 14 (2012) 2807-2815. https://doi.org/10.1039/c2gc35832h

[10] M. Keller, V. Colliere, O. Reiser, A.M. Caminade, J.P. Majoral, A. Ouali, Angew. Chem. Int. Ed., 52 (2013) 3626-3629. https://doi.org/10.1002/anie.201209969

[11] V. Maraval, R. Laurent, A.M. Caminade, J.P. Majoral, Organometallics, 19 (2000) 4025-4029. https://doi.org/10.1021/om0005607

[12] M. Koprowski, R.M. Sebastian, V. Maraval, M. Zablocka, V. Cadierno, B. Donnadieu, A. Igau, A.M. Caminade, J.P. Majoral, Organometallics, 21 (2002) 4680-4687. https://doi.org/10.1021/om011076m

[13] L. Martins, R. Wanke, T.F.S. Silva, A.J.L. Pombeiro, P. Servin, R. Laurent, A.M. Caminade, Molecules, 23 (2018). https://doi.org/10.3390/molecules23123066

[14] E. Badetti, A.M. Caminade, J.P. Majoral, M. Moreno-Manas, R.M. Sebastian, Langmuir, 24 (2008) 20902101. https://doi.org/10.1021/la7013418

[15] R. Laurent, A.M. Caminade, J.P. Majoral, Tetrahedron Lett., 46 (2005) 6503-6506.

https://doi.org/10.1016/j.tetlet.2005.07.100

[16] L. Routaboul, S. Vincendeau, C.O. Turrin, A.M. Caminade, J.P. Majoral, J.C. Daran, E. Manoury, J. Organomet. Chem., 692 (2007) 1064-1073. https://doi.org/ 10.1016/j.jorganchem.2006.10.065

[17] N.G. Garcia-Pena, A.M. Caminade, A. Ouali, R. Redon, C.O. Turrin, RSC Advances, 6 (2016) 64557-64567. https://doi.org/10.1039/c6ra13709a

[18] P. Servin, R. Laurent, L. Gonsalvi, M. Tristany, M. Peruzzini, J.P. Majoral, A.M. Caminade, Dalton Trans., (2009) 4432-4434. https://doi.org/10.1039/b906393p 
[19] P. Servin, R. Laurent, H. Dib, L. Gonsalvi, M. Peruzzini, J.P. Majoral, A.M. Caminade, Tetrahedron Lett., 53 (2012) 3876-3879. https://doi.org/10.1016/j.tetlet.2012.05.070

[20] P. Servin, R. Laurent, M. Tristany, A. Romerosa, M. Peruzzini, F. Garcia-Maroto, J.-P. Majoral, A.-M. Caminade, Inorg. Chim. Acta, 470 (2018) 106-112. https://doi.org/10.1016/j.ica.2017.04.044

[21] P. Neumann, H. Dib, A. Sournia-Saquet, T. Grell, M. Handke, A.M. Caminade, E. Hey-Hawkins, Chem.-Eur. J., 21 (2015) 6590-6604. https://doi.org/10.1002/chem.201406489

[22] P. Neumann, H. Dib, A.M. Caminade, E. Hey-Hawkins, Angew. Chem. Int. Ed., 54 (2015) 311-314. https://doi.org/10.1002/anie.201408314

[23] L. Garcia, A. Roglans, R. Laurent, J.P. Majoral, A. Pla-Quintana, A.M. Caminade, Chem.Commun., 48 (2012) 9248-9250. https://doi.org/10.1016/10.1039/c2cc32992a

[24] A. Perrier, M. Keller, A.M. Caminade, J.P. Majoral, A. Ouali, Green Chem., 15 (2013) 2075-2080. https://doi.org/ 10.1039/c3gc40720a

[25] A.M. Caminade, A. Ouali, R. Laurent, C.O. Turrin, J.P. Majoral, Chem. Soc. Rev., 44 (2015) 3890-3899. https://doi.org/10.1039/c4cs00261j

[26] N. Launay, A.M. Caminade, R. Lahana, J.P. Majoral, Angew. Chem.-Int. Edit. Engl., 33 (1994) 1589-1592. https://doi.org/10.1002/anie.199415891

[27] M. Slany, M. Bardaji, M.J. Casanove, A.M. Caminade, J.P. Majoral, B. Chaudret, J. Am. Chem. Soc., 117 (1995) 9764-9765. https://doi.org/10.1021/ja00143a023

[28] M.L. Lartigue, B. Donnadieu, C. Galliot, A.M. Caminade, J.P. Majoral, J.P. Fayet, Macromolecules, 30 (1997) 7335-7337. https://doi.org/10.1021/ma970570s

[29] A.M. Caminade, A. Ouali, R. Laurent, C.O. Turrin, J.P. Majoral, Coord. Chem. Rev., 308 (2016) 478-497. https://doi.org/10.1016/j.ccr.2015.06.007

[30] N. El Brahmi, S. El Kazzouli, S. Mignani, M. Bousmina, J.P. Majoral, Tetrahedron, 69 (2013) 3103-3133. https://doi.org/10.1016/j.tet.2013.02.019

[31] A. Ouali, R. Laurent, A.M. Caminade, J.P. Majoral, M. Taillefer, J. Am. Chem. Soc., 128 (2006) 15990-15991. https://doi.org/10.1021/ja066505s

[32] A. Gissibl, C. Padie, M. Hager, F. Jaroschik, R. Rasappan, E. Cuevas-Yanez, C.O. Turrin, A.M. Caminade, J.P. Majoral, O. Reiser, Org. Lett., 9 (2007) 2895-2898. https://doi.org/10.1021/ol071128p

[33] M. Keller, M. Ianchuk, S. Ladeira, M. Taillefer, A.M. Caminade, J.P. Majoral, A. Ouali, Eur. J. Org. Chem., (2012) 1056-1062. https://doi.org/10.1002/ejoc.201101521

[34] N. El Brahmi, S. El Kazzouli, S.M. Mignani, E. Essassi, G. Aubert, R. Laurent, A.M. Caminade, M.M. Bousmina, T. Cresteil, J.P. Majoral, Mol. Pharm., 10 (2013) 1459-1464. https://doi.org/10.1021/mp4000184

[35] M.F. Ottaviani, N. El Brahmi, M. Cangiotti, C. Coppola, F. Buccella, T. Cresteil, S. Mignani, A.M. Caminade, J.P. Costes, J.P. Majoral, RSC Advances, 4 (2014) 36573-36583. https://doi.org/10.1039/c4ra06066k

[36] S. Mignani, N. El Brahmi, L. Eloy, J. Poupon, V. Nicolas, A. Steinmetz, S. El Kazzouli, M.M. Bousmina, M. Blanchard-Desce, A.M. Caminade, J.P. Majoral, T. Cresteil, Eur. J. Med. Chem., 132 (2017) 142-156. https://doi.org/10.1016/j.ejmech.2017.03.035

[37] S.M. Mignani, N. El Brahmi, S. El Kazzouli, R. Laurent, S. Ladeira, A.-M. Caminade, E. Pedziwiatr-Werbicka, E.M. Szewczyk, M. Bryszewska, M.M. Bousmina, T. Cresteil, J.-P. Majoral, Mol. Pharm., 14 (2017) 4087-4097. https://doi.org/10.1021/acs.molpharmaceut.7b00771

[38] L. Chen, S. Mignani, A.-M. Caminade, J.-P. Majoral, Wiley Interdisciplinary Reviews-Nanomedicine and Nanobiotechnology, 11 (2019) 1577. https://doi.org/10.1002/wnan.1577

[39] A.-M. Caminade, A. Hameau, J.-P. Majoral, Dalton Trans., 45 (2016) 1810-1822.

https://doi.org/10.1039/c5dt03047a

[40] L. Chen, Y. Fan, J. Qiu, R. Laurent, J. Li, J. Bignon, S. Mignani, A.-M. Caminade, X. Shi, J.-P. Majoral, Chem.-

Eur. J., 26 (2020) 5903-5910. https://doi.org/10.1002/chem.202001014 